\title{
Coloring the environment: Hue, arousal, and boredom
}

\author{
THOMAS C. GREENE, PAUL A. BELL, and WILLIAM N. BOYER
}

\section{Colorado State University, Fort Collins, Colorado}

\begin{abstract}
One hundred and forty undergraduate subjects, sitting in carrels having side panels painted either light blue, blue, pink, red, orange, white, brown, green, yellow, or gray were exposed to procedures designed to induce boredom. Subjects listened to a tape that repeated one of two words every $2 \mathrm{sec}$ for $10 \mathrm{~min}$. The results showed that self-reported arousal and evaluations of the environment were higher in the yellow condition than in the other color conditions. Response to boredom-induction procedures did not vary with color or saturation.
\end{abstract}

Although there is a vast body of scientific literature on the perception of color, the findings on the effects of color on human feelings and behavior seem to be largely speculative in nature. For example, it is widely held that hues toward the "warm" (red, orange) end of the spectrum induce more feelings of warmth than do those toward the "cool" (green, blue) end of the spectrum (Birren, 1961). To date, most of the reported data have failed to support this popular notion (e.g., Greene \& Bell, 1980). Similarly, many investigators have suggested that red and orange hues are more arousing than green and blue hues (Birren, 1961; Goldstein, 1942; Ketcham, 1958). Although there is some empirical support for this belief (Gerard, 1958; Goldstein, 1942; Nourse \& Welch, 1971; Smith, 1958; Wilson, 1966), the observed differences have been either minimal, overstated, or experimentally confounded (Nakshian, 1964; Norman \& Scott, 1952). Besides the differences in preference or semantic associations, the impact of color on behavior still remains an open issue (e.g., Goodfellow \& Smith, 1973). Nevertheless, if color does affect behavior, the effects would be of great interest to many individuals, such as designers and environmental psychologists. That is, arousing hues might be employed to prevent boredom and to maintain activity, whereas passive hues might be used to facilitate calm and order for individuals who are undesirably "hyperactive." Consequently, the present research was designed to determine the effects of 10 different hues and saturations on boredom. Specifically, we hypothesized that red, orange, and yellow hues would be more effective in resisting boredom than would green or blue hues.

\section{METHOD}

The subjects were 140 undergraduates ( 70 males, 70 females) enrolled in a general psychology course at Colorado State Uni-

Requests for reprints should be sent to Thomas C. Greene, now at the Department of Psychology, St. Lawrence University, Canton, New York 13617. versity. The subjects were tested individually. They were seated initially at a table in the reception room, where they completed Mehrabian and Russell's (1974) Emotional Response Scale (ERS). This scale is a bipolar adjective instrument composed of subscales assessing subjective pleasure, arousal, and dominance. All subjects also completed Griffitt's (1970) Personal Feelings Scale (PFS), a similar instrument assessing subjective comfort. Upon completion of these intial forms, each of the subjects was ushered into a $2.7 \times 4.0 \mathrm{~m}$ laboratory room and seated at a triangular carrel with walls extending $1.2 \mathrm{~m}$ above table height. Upon the two sides of the carrel walls were mounted $1.1 \mathrm{x}$ $1.0 \mathrm{~m}$ panels painted in one of 10 colors (Sears brand enamel trim paint): light blue, blue, pink, red, orange, white, brown, green, yellow, or gray. After being seated at the table, the subjects again completed the ERS and PFS and then Russell and Pratt's (1980) Affective Quality of Place Scale (AQPS).

The subjects then were exposed to a boredom-induction procedure similar to that employed by Calef, Calef, Piper, Wilson, and Geller (1977). The technique required the subjects to monitor a 10-min audio tape in which the word "door" was repeated at 2-sec intervals for $60 \mathrm{sec}$, followed by the word "chair" for $30 \mathrm{sec}$, and then the word "door" again for the remaining $8.5 \mathrm{~min}$. The subjects were instructed to listen carefully to each word, and to record on a numbered response sheet every time the word seemed to change. After the boredom induction, the subjects again filled out the ERS, PFS, and AQPS. Upon completion of these forms, the subjects were debriefed and thanked for participating in the study.

\section{RESULTS}

One-way analyses of variance conducted on initial measures of the ERS and PFS indicated no significant differences between the subject groups prior to treatment. Similar analyses, along with Newman-Keuls tests $(p<.05)$, on the ERS, PFS, and AQPS taken immediately after exposure to the color treatments revealed significant color differences for the AQPS pleasantunpleasant dimension $[F(9,130)=2.59, \mathrm{p}<.009]$, with the yellow color (mean $=-0.77$ ) being rated more pleasant than the white $($ mean $=-2.17)$, brown (mean $=$ $-2.10)$, or gray (mean $=-1.79)$ hue. The data from the arousing-sleepy dimension of the AQPS also showed more arousal for the orange (mean $=1.24)$ and yellow $($ mean $=1.44)$ color than for the brown $($ mean $=-1.94)$ 
or gray $($ mean $=-1.57)$ color $[F(9 ; 130)=2.93, \mathrm{p}<.003]$. In addition, the exciting-gloomy dimension showed more arousal $[\mathrm{F}(9,130)=3.40, \mathrm{p}<.0009]$ for the yellow $($ mean $=1.04)$ than for the brown $($ mean $=-2.44)$, gray $($ mean $=-2.34)$, or white $($ mean $=-2.19)$ hue. The only other significant effect prior to the boredom induction was on the arousal subscale of the ERS $[F(9,130)=$ $2.38, \mathrm{p}<.02]$, with subjects in the yellow-colored $($ mean $=30.79)$ environment reporting more arousal than those in the white (mean $=23.57)$ condition.

The boredom-induction procedures had no reliable effects on any dependent measures. Also, one-way analyses of variance on the posttreatment data showed only that the yellow color (mean $=0.47$ ) was more arousing than either the white (mean $=-2.34$ ) or gray (mean $=-2.43)$ color on the arousing-sleepy dimension of the AQPS $[F(9,130)=2.60, p<.008]$. Finally, no analyses revealed significant sex differences.

\section{DISCUSSION}

The present results appear to suggest that only the yellow hue prompted a more favorable evaluation of the subjects' environment. However, the yellow hue did not appear to influence the person's feeling of boredom. Interestingly, by the final administration of the scales, many of the color effects seem to have attenuated. Although yellow continued to be associated with the most positive environmental assessments, including the degree to which the environment was arousing, there were no significant differences in the individual's subjective affect or arousal. The current findings and those reported by others (see Nourse \& Welch, 1971) seem to suggest that the color treatments are most effective shortly after initial exposure.

Several changes in future studies of this type might expand the generality of their results. While two levels of saturation were employed for the blue and red hues, further research might examine various combinations of hue, brightness, and saturation. It might also be interesting to see what effect a larger colored proportion of the subject's field of vision might have on the person's behavior. Furthermore, alternative boredom-induction techniques might also be employed. Although the subjects in the present study verbally reported being bored, such boredom was not indicated in their self-reports of arousal. It is possible that requiring subjects to attend to the repetitious words might counter their feelings of boredom (see Calef et al., 1977). Whatever the interpretation, the present results do not lend support to popular notions that color in the environment has any substantial impact on human behavior.

\section{REFERENCES}

Birren, F. Color psychology and color therapy. New York: University Books, 1961.

Calef, R. S., Calef, R. A., Piper, D., Wilson, S. A., \& Geller, E. S. Imagined verbal transformations as a function of age and verbal intelligence. Bulletin of the Psychonomic Society, 1977, 10, 109-110.

Gerard, R. M. Differential effects of color lights on psychophysiological functions. Unpublished doctoral dissertation. University of California, Los Angeles, 1958.

Goldstein, K. Some experimental observations concerning the influence of colors on the functions of the organism. Occupational Therapy, 1942, 21, 147-151.

Goodfellow, R. A. H., \& Smith, P. C. Effects of environmental color on two psychomotor tasks. Perceptual and Motor Skills, 1973, 37, 296-298.

Greene, T. C., \& Bell, P. A. Additional considerations concerning the effects of 'warm' and 'cool' wall colors on energy conservation. Ergonomics, 1980, 32, 949-954.

GRIFFITT, W. Environmental effects on interpersonal affective behavior: Ambient effective temperature and attraction. Journal of Personality and Social Psychology, 1970, 15, 240-244.

KетCHAM, H. Color planning for business and industry. New York: Harper, 1958.

Mehrabian, A., \& Russell, J. A. The basic emotional impact of environments. Perceptual and Motor Skills, 1974, 38, 283-301.

NaKshian, J. S. The effects of red and green surroundings on behavior. Journal of General Psychology, 1964, 70, 143-161.

Norman, R. D., \& Scotт, W. A. Color and affect: A review and semantic evaluation. Journal of General Psychology, 1952, 46, $185-223$

Nourse, J. C., \& Welch, R. B. Emotional attributes of color: A comparison of violet and green. Perceptual and Motor Skills, 1971, 32, 403-406.

Russell, J. A., \& Pratt, G. A description of the affective quality attributed to environments. Journal of Personality and Social Psychology, 1980, 38, 311-322.

Smith, R. S. An investigation of the relationship between physiological and cognitive measures of affective response to color. Unpublished doctoral dissertation, University of Pennsylvania, 1958.

Wilson, G. D. Arousal properties of red vs. green. Perceptual and Motor Skills, 1966, 23, 947-949.

(Manuscript received for publication April 22, 1983). 